\title{
miR-98-5p contributes to cisplatin resistance in epithelial ovarian cancer by suppressing miR-152 biogenesis via targeting Dicer 1
}

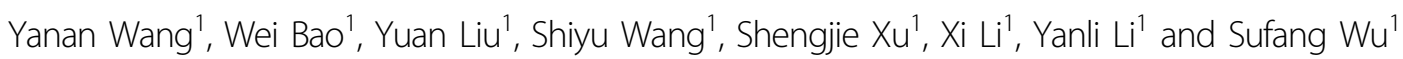

\begin{abstract}
Epithelial ovarian cancer (EOC) is a highly lethal gynecological malignancy, and cisplatin resistance is usually correlated with the poor prognosis of EOC. Increasing evidence indicates that the dysregulation of miRNAs is related to chemotherapy sensitivity. In this study, we revealed that miR-98-5p, a member of the let-7 family, was enriched in cisplatin-resistant EOC cells compared with cisplatin-sensitive cells, and could promote cisplatin resistance in EOC cells. Further studies showed that miR-98-5p could directly target the 3'-UTR of Dicer1 and suppress its expression, causing global miRNA downregulation. By miRNA array and qRT-PCR verification, we identified miR-152 as the vital downstream target of the miR-98-5p/Dicer1 axis in EOC cells. Moreover, we demonstrated that the ectopic expression of miR-152 reversed cisplatin resistance both in vitro and in vivo by targeting RAD51, a central member in homologous recombination. Importantly, miR-98-5p expression, as determined by in situ hybridization in tumor tissues, was associated with poor outcome of EOC patients. Together, these findings suggest the essential role of the miR-98-5p/ Dicer1/miR-152 pathway in regulating cisplatin resistance of EOC cells and provide a potential target for EOC therapy.
\end{abstract}

\section{Introduction}

Epithelial ovarian cancer(EOC) is the leading cause of deaths from gynecological malignancy in the developed world ${ }^{1}$. Due to the absence of specific symptoms in the early stages and the heterogeneous nature of this disease, more than two-thirds of patients cannot be diagnosed until an advanced stage ${ }^{2}$. The current standard treatment in patients with EOC is debulking surgery followed by platinum-based chemotherapy. However, $\sim 25 \%$ of patients will develop resistance within 6 months after platinum-based chemotherapy ${ }^{3}$. The overall five-year survival rate for patients with advanced EOC is only

Correspondence: Yanli Li (liecho121@126.com) or

Sufang Wu (wsf_sfph@sjtu.edu.cn)

'Department of Obstetrics and Gynecology, Shanghai General Hospital,

Shanghai Jiao Tong University School of Medicine, Shanghai, China

These authors contributed equally: Yanan Wang, Wei Bao.

Edited by ML Asselin-labat
$30-40 \%$, and acquired resistance to platinum is considered a major factor in disease relapse. Therefore, it is crucial to investigate the mechanisms of platinum resistance in EOC patients and develop new strategies for EOC treatment.

MicroRNAs (miRNAs) are a class of non-proteincoding $\operatorname{RNAs}(\sim 22 \mathrm{nt})$ that can act as post-transcriptional regulators by binding to the $3^{\prime}$-untranslated region $\left(3^{\prime}\right.$ UTR) of target mRNAs. Functional mature miRNAs arise from several post-transcriptional processing steps including cutting by Drosha/DGCR8 to pre-miRNA in the nucleus, exporting to the cytoplasm, and cleaving by the RNaseIII Dicer ${ }^{4-6}$. Several studies have shown a global decrease of mature miRNA expression in cancer cells, suggesting that miRNA biogenesis might be impaired in human cancers ${ }^{7,8}$. Additionally, low Dicer expression level has been significantly associated with advanced tumor

\section{(c) The Author(s) 2018}

(c) (i) Open Access This article is licensed under a Creative Commons Attribution 4.0 International License, which permits use, sharing, adaptation, distribution and reproduction cc) in any medium or format, as long as you give appropriate credit to the original author(s) and the source, provide a link to the Creative Commons license, and indicate if changes were made. The images or other third party material in this article are included in the article's Creative Commons license, unless indicated otherwise in a credit line to the material. If material is not included in the article's Creative Commons license and your intended use is not permitted by statutory regulation or exceeds the permitted use, you will need to obtain permission directly from the copyright holder. To view a copy of this license, visit http://creativecommons.org/licenses/by/4.0/. 


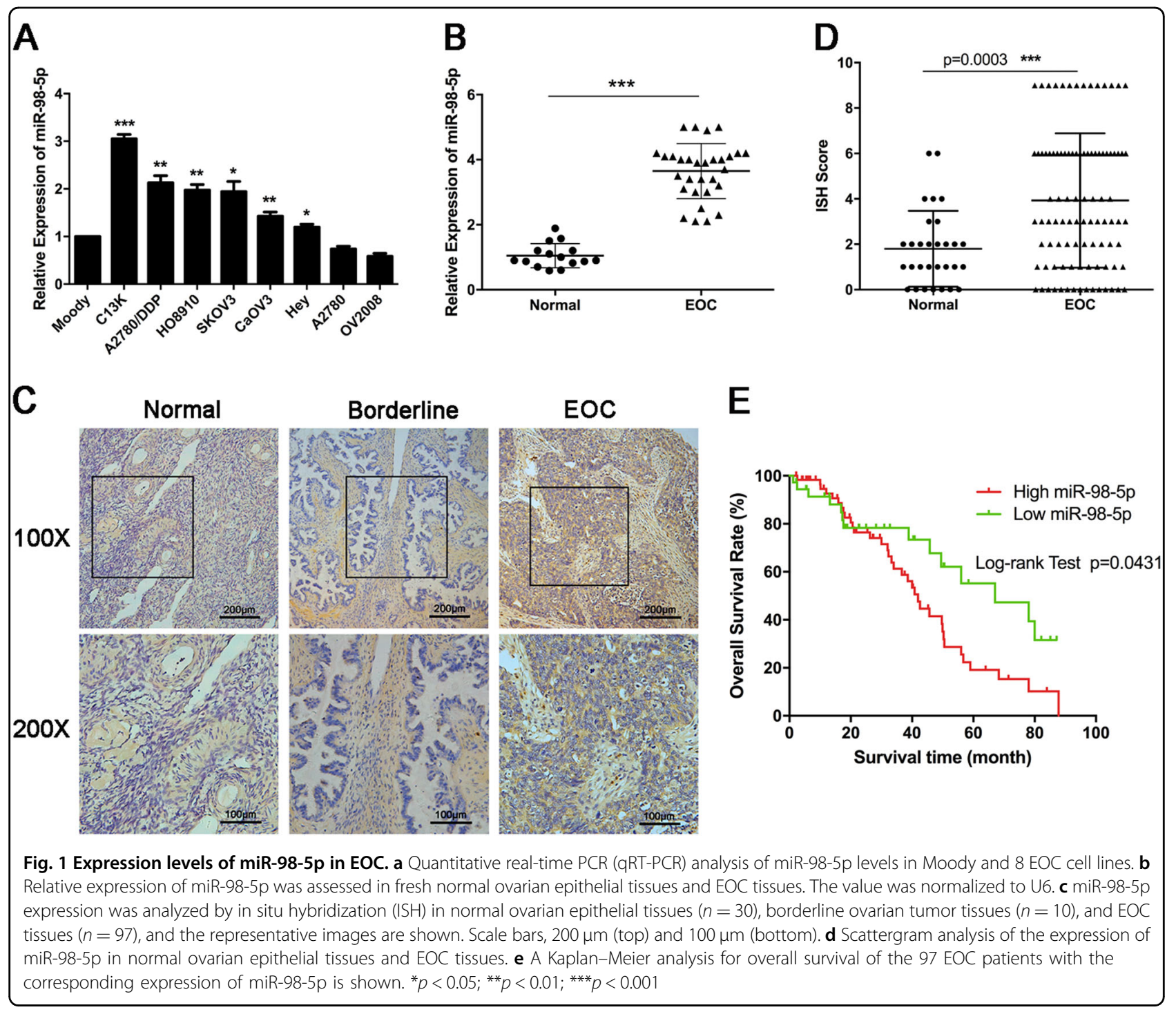

stage and poor clinical outcomes among patients with EOC $^{9}$. However, the underlying mechanisms or the biological advantages afforded to cells by reduced miRNA expression in cancers remains not fully illustrated.

The let-7 family is one of the earliest and most classic mammalian miRNAs identified ${ }^{10,11}$. The let-7 family is comprised of 13 family members located on 9 different chromosomes whose expression in most human malignancies is usually deregulated, reduced, or lost ${ }^{12}$. Importantly, it has been reported that Dicer1 is a direct target of let-7, which impacts the expression of other miRNAs ${ }^{13}$.

Previous findings identified miR-98-5p, a member of let-7 family, as a potent tumor suppressor downregulated in various cancer types, such as nasopharyngeal carcinoma ${ }^{14}$ and endometrial cancer ${ }^{15}$. However, miR-98 was also found to be upregulated in primary breast cancer specimens ${ }^{16}$, and expressed at higher levels in small cell lung cancer cell lines than immortalized human bronchial epithelial cells ${ }^{17}$. These results suggest that miR-98 may display absolutely contrary function in different types of cancers. However, few studies report the function of miR98-5p in EOC.

In the present study, we identified miR-98-5p, a member of let-7 family, whose expression is associated with cisplatin resistance and poor outcome in EOC patients. Elevated miR-98-5p significantly promoted resistance of EOC cells to cisplatin treatment. Moreover, enforced miR-98-5p expression inhibited the expression of Dicer1, causing global miRNA downregulation. Specifically, by miRNA array, we identified miR-152 as the vital downstream target of the miR-98-5p/Dicer1 axis in EOC cells. Although a considerable amount of evidence indicates that miR-98 functions as a tumor suppressor, our data, for the first time, revealed that miR-98-5p could induce cisplatin resistance in EOC by suppressing the expression of miR-152 through directly targeting Dicer1. Our study 
provides a better understanding of the cisplatin resistance related mechanism in EOC, and offers miR-98-5p and miR-152 as potential therapeutic targets for cisplatinresistant EOC.

\section{Results}

miR-98-5p expression in EOC

To investigate the role of miR-98-5p in the pathogenesis of EOC, we first examined its expression in EOC cell lines and clinical tissue specimens. We performed qRT-PCR to test the expression level of miR-98-5p in an immortalized human ovarian epithelial cell line (Moody) and eight EOC cell lines. The results demonstrated that the six EOC cell lines produced a greater amount of miR-98-5p than Moody (Fig. 1a). To verify the roles of miR-98-5p in clinical samples, we also detected endogenous expression levels of miR-98-5p in fresh normal ovarian epithelial tissues $(n=15)$ and EOC tissues $(n=30)$ using qRT-PCR (Fig. 1b). The expression levels of miR-98-5p were remarkably higher in EOC tissues than those in normal epithelial tissues. Furthermore, we determined the levels of miR-98-5p expression by in situ hybridization in another series of 97 EOC patients, for which clinical and prognosis data were available. The results showed that miR-98-5p was highly expressed in EOC tissues relative to normal tissues and borderline tumor tissues (Fig. 1c, d). We then analyzed the association between miR-98-5p and the clinic-pathological parameters of these EOC patients (Table 1). We found that expression of miR-98-5p was not statistically associated with age, stage, histology type, grade, or lymph node metastasis. However, high miR-98$5 \mathrm{p}$ expression was associated with poor therapy response and platinum resistance. Moreover, Kaplan-Meier analysis indicated a significant correlation between high miR98-5p expression and poor overall survival (OS) of EOC patients (Fig. 1e).

Taken together, these data confirmed the overexpression of miR-98-5p in EOC, which is associated with platinum resistance and predicts poor prognosis in EOC patients.

Roles of miR-98-5p and other members in let-7 family in cisplatin sensitivity of EOC cells

We confirmed the cisplatin resistance of the EOC cell line $\mathrm{C} 13^{*}$ compared with the cisplatin-sensitive OV2008 cell line using CCK- 8 assay. We found that the $50 \%$ inhibitory concentration (IC50) of cisplatin in the C13* cells was $\sim 2.5$-fold that of OV2008 cells (Fig. 2a). The experiment was repeated in another cisplatin-resistant EOC cell line A2780/DDP and its cisplatin-sensitive parental A2780. The results showed that the IC50 of A2780/DDP cells was two-fold that of A2780 cells (Fig. 2a). Then, we performed qRT-PCR to measure the expression levels of 7 members of the let- 7 family in
Table 1 The clinic-pathological characteristics of EOC patients and association with miR-9 expression

\begin{tabular}{|c|c|c|c|c|}
\hline \multirow[t]{2}{*}{ Variables } & \multirow{2}{*}{$\begin{array}{l}\text { Total } \\
(n=97) \\
\text { No. }\end{array}$} & \multicolumn{2}{|l|}{ miR-98-5p } & \multirow[t]{2}{*}{$P$-value } \\
\hline & & $\begin{array}{l}\operatorname{Low}(n=36) \\
\text { No. }(\%)\end{array}$ & $\begin{array}{l}\text { High }(n=61) \\
\text { No. }(\%)\end{array}$ & \\
\hline \multicolumn{5}{|l|}{ Age } \\
\hline$<50$ & 42 & $17(47.2)$ & $25(41.0)$ & \multirow[t]{2}{*}{0.5491} \\
\hline$\geq 50$ & 55 & $19(52.8)$ & $36(59.0)$ & \\
\hline \multicolumn{5}{|l|}{ FIGO stage } \\
\hline$|-| \mid$ & 30 & $13(36.1)$ & $17(27.9)$ & \multirow[t]{2}{*}{0.3962} \\
\hline III-IV & 67 & $23(63.9)$ & $44(72.1)$ & \\
\hline \multicolumn{5}{|l|}{ Histology type } \\
\hline Serous & 62 & $23(63.9)$ & $39(63.9)$ & \multirow[t]{4}{*}{0.9865} \\
\hline Mucinous & 22 & $8(22.2)$ & $14(23.0)$ & \\
\hline Clear cell & 6 & $2(5.6)$ & $4(6.6)$ & \\
\hline Endometrioid & 7 & $3(8.3)$ & $4(6.6)$ & \\
\hline \multicolumn{5}{|l|}{ Differentiation } \\
\hline G1 & 46 & $20(55.6)$ & $26(42.6)$ & \multirow[t]{3}{*}{0.4508} \\
\hline $\mathrm{G} 2$ & 27 & $8(22.2)$ & $19(31.2)$ & \\
\hline G3 & 24 & $8(22.2)$ & $16(26.2)$ & \\
\hline \multicolumn{5}{|l|}{ Lymph nodes } \\
\hline Negative & 45 & $13(36.1)$ & $32(52.5)$ & \multirow[t]{2}{*}{0.1188} \\
\hline Positive & 52 & $23(63.9)$ & $29(47.5)$ & \\
\hline \multicolumn{5}{|c|}{ Response to primary therapy } \\
\hline$C R$ & 66 & 29 (80.6) & $37(60.7)$ & \multirow[t]{2}{*}{$0.0423^{*}$} \\
\hline Non-CR & 31 & $7(19.4)$ & $24(39.3)$ & \\
\hline \multicolumn{5}{|l|}{ Platinum status } \\
\hline Sensitive & 58 & $27(75.0)$ & $31(50.8)$ & \multirow[t]{2}{*}{$0.0190^{*}$} \\
\hline Resistant & 39 & $9(25.0)$ & $30(49.2)$ & \\
\hline
\end{tabular}

Platinum resistance or sensitivity was defined as relapse or progression within 6 months or after 6 months from the last platinum-based chemotherapy, respectively.

$C R$ complete response

${ }^{*} p<0.05$

chemo-resistant and chemo-sensitive EOC cells. Let-7c$5 p$, let-7e-5p, and let-7g-5p were increased only in A2780/ DDP cells, whereas miR-98-5p was upregulated in both C13* and A2780/DDP cells. The expression of the remaining miRNAs was similar in chemo-resistant and the relative chemo-sensitive cells (Fig. 2b).

Furthermore, to investigate roles of miR-98-5p in cisplatin-induced cytotoxicity, A2780 and OV2008 cells were transiently transfected with miR-98-5p mimic, and then exposed to different concentrations of cisplatin for $48 \mathrm{~h}$ and assessed by CCK 8 assay. We found that miR-98$5 \mathrm{p}$ overexpression markedly increased the cisplatin 


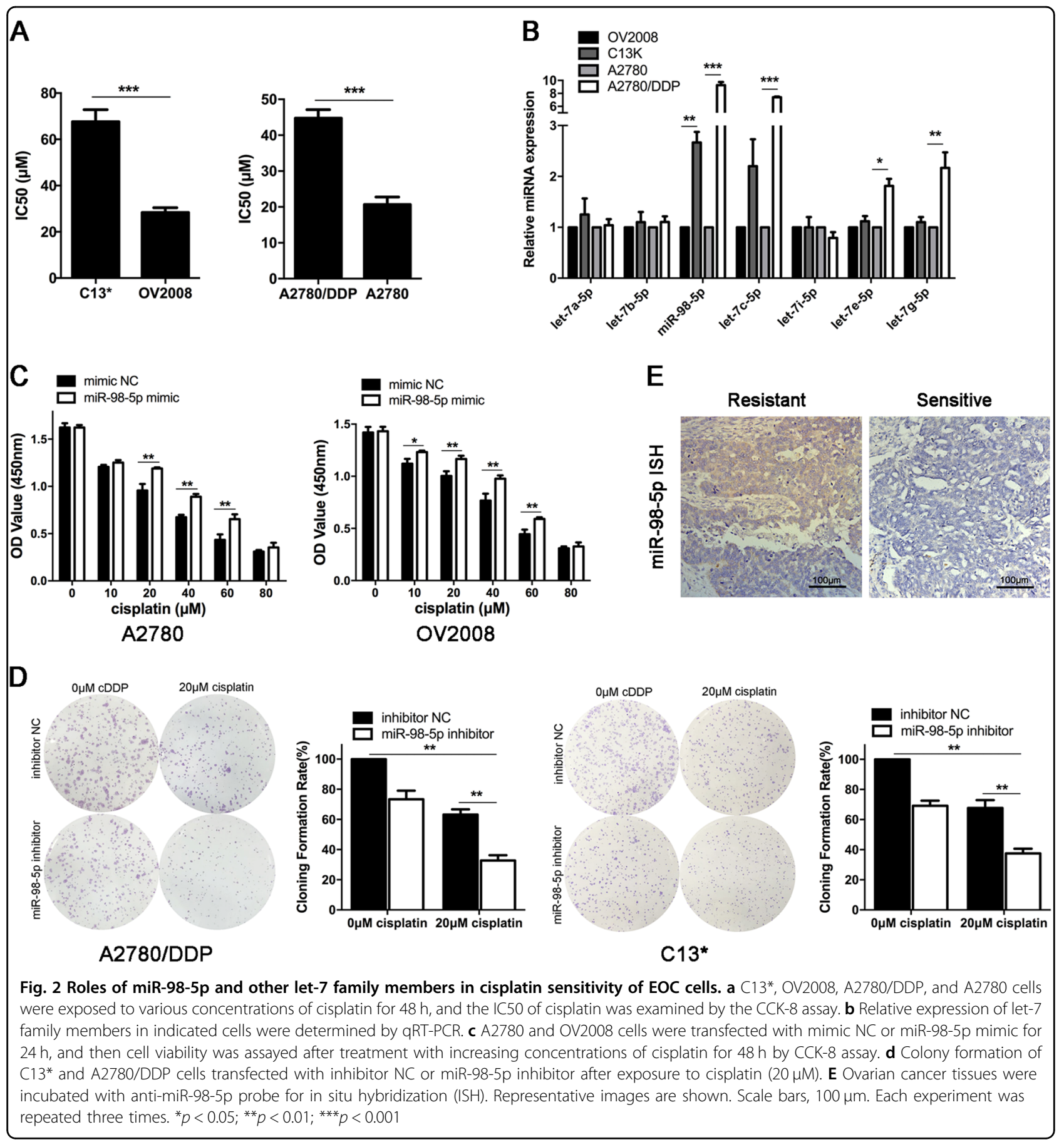

resistance of EOC cells (Fig. 2c). Meanwhile, miR-98-5p inhibitor transfected cells significantly repressed colony formation and cell viability with cisplatin treatment (Fig. 2d and Supplementary Figure 1A). It is worth noting that HO8910, SKOV3, CaOV3, and Hey cells are not cisplatin-resistant cell lines, and the increased sensitivity to cisplatin of the 4 cell lines after downregulating miR$98-5 p$ is a relative change. The efficacy of miR-98-5p overexpression and inhibition were verified by qRT-PCR (Supplementary Figure 1B). In addition, Fig. 2e shows the representative photographs of miR-98-5p expression in cisplatin-sensitive and cisplatin-resistant EOC tissues with in situ hybridization method. These data indicated that miR-98-5p was overexpressed in cisplatin-resistant EOC cells and tissues, and the downregulation of miR-98$5 p$ could promote the cisplatin sensitivity of EOC cells. 


\section{Dicer1 is a direct target of miR-98-5p in EOC cells}

Evidence has suggested that Dicer1 is a direct target of let-7 family ${ }^{13}$, and the downregulation of Dicer1 contributes to cisplatin resistance in EOC cells ${ }^{18}$. However, the abundance of miRNAs or their targets in different cell types may show opposite outcomes, and miRNAs may perform different functions in different cell types by regulating their target genes ${ }^{19}$. We transfected A2780 cells with $50 \mathrm{nM}$ mimics of let-7 family members and found that these miRNAs significantly inhibited Dicer1 protein expression, with miR-98-5p showing the greatest suppression effect (Supplementary Figure 2). Furthermore, we observed that the downregulation of Dicer1 markedly increased the cisplatin resistance of EOC cells with CCK- 8 assay (Supplementary Figure 3).

Next, we examined whether miR-98-5p, a member of let-7 family, could directly modulate Dicer1 and phenotypes in EOC cells. Two bioinformatics algorithms, TargetScan (http://www.targetscan.org) and miRanda (http:// www.microrna.org/microrns/home.do), predicted that Dicer1 is a potential target of miR-98-5p. Indeed, we further observed that Dicer1 was significantly reduced at both mRNA and protein levels after miR-98-5p overexpression and, conversely, increased by the transfection of miR-98-5p inhibitor in both C13* and A2780/DDP cells (Fig. 3a, b). We then performed the dual-reporter luciferase assay in $293 \mathrm{~T}$ cells to examine whether miR-98-5p could directly bind to the $3^{\prime}$-UTR of Dicer1. Transfection with miR-98-5p mimic reduced the luciferase activity of the construct, compared with mimic NC-transfected cells. However, upon site-directed mutagenesis of the putative miR-98-5p binding sites in these constructs (Fig. 3c, d), miR-98-5p lost the ability to downregulate luciferase activity (Fig. 3e, f).

Together, the data identified Dicer1 as a genuine target of miR-98-5p, which appeared to be involved in EOC development.

\section{miR-152 is markedly decreased in miR-98-5p/Dicer1 axis-} regulating samples

We further sought to address the expression pattern of miRNAs in the downstream of miR-98-5p/Dicer1 axis. We conducted miRNA sequencing (Supplementary Excels) to identify differentially expressed miRNAs in miR-98-5p-transfected cells, and then a heatmap analysis was undertaken (Fig. 4a). The miRNA-sequence and analysis work was repeated in si-Dicer1-transfected cells (Fig. 4b). Additionally, the efficiency of transfection was determined by qRT-PCR analysis (Fig. 4c). Furthermore, we analyzed the downregulated miRNAs in miR-98-5p upregulated cells and dicer1 downregulated cells, and the Venn diagram revealed that 8 miRNAs were downregulated both in the two treatment groups (Fig. 4d).
To further confirm the robustness of the sequencing results shown above, we performed qRT-PCR assay to quantify the expressions of the 8 miRNAs in 4 treatment groups (Fig. 4e, f). Notably, miR-152 downexpression was most pronounced in miR-98-5p upregulated and Dicer1 downregulated cells compared with the negative control cells. Strikingly, the suppression effect of miR-98-5p on miR-152 was absolutely eliminated by the overexpression of Dicer1. In contrast, such an obvious change was not observed in the expression of the other 7 miRNAs. In addition, Fig. 4g shows that miR-152 is remarkably downregulated by miR-98-5p compared with the other members of the let-7 family. This result suggests that miR-152 is likely a vital and functional downstream regulator of the miR-98-5p/Dicer1 pathway.

\section{Effects of miR-152 on the cisplatin sensitivity of EOC cells in vitro and in vivo}

There has been a rapid increase in the number of studies focusing on miR-152 in recent years, which demonstrated that the expression of miR-152 was inhibited in various tumors, including ovarian ${ }^{20}$, hepatocellular ${ }^{21}$, and breast cancer $^{22}$. These findings revealed that miR-152 may function as a tumor suppressor in human cancer. To further understand the role of miR-152 in cisplatininduced cytotoxicity, miR-152 mimic was transfected into drug-resistant EOC cells C13* and A2780/DDP cells. The transfection efficiency was evaluated at $48 \mathrm{~h}$ after transfection (Supplementary Figure 4). The results by CCK-8 assay revealed that miR-152 overexpression sensitized C13* and A2780/DDP cells to cisplatin (Fig. 5a). Furthermore, we performed a colony formation assay and found that cells transfected with miR-152 mimic demonstrated reduced colony formation rates compared with $\mathrm{NC}$ after exposure to $20 \mu \mathrm{M}$ cisplatin (Fig. 5b). We next performed a flow cytometry assay to investigate the function of miR-152 in cisplatin-induced apoptosis, and a higher proportion of apoptotic cells was observed in miR152 overexpression cells compared with control cells (Fig. 5c). These data indicated that miR-152 could promote the cisplatin sensitivity of EOC cells.

To further demonstrate the role of miR-152 in chemosensitization, we used miR-152 agomiR, a cholesterolconjugated 2'-O-methyl-modified miR-152 with pharmacokinetic properties, for in vivo studies ${ }^{23}$. According to the treatment, the tumors on the mice were actually assigned to the following groups: (1) agomiR-NC + NS, (2) agomiR-152 + NS, (3) agomiR-NC + cisplatin, and (4) agomiR-152 + cisplatin (Fig. 5d). As shown in Figs. 5e, f, the average xenograft volume and weight of agomiR-152 plus cisplatin group at 38 days were statistically significantly decreased compared with the other three groups. Moreover, immunohistochemistry assay showed that the tumors treated with agomiR-152 plus cisplatin 


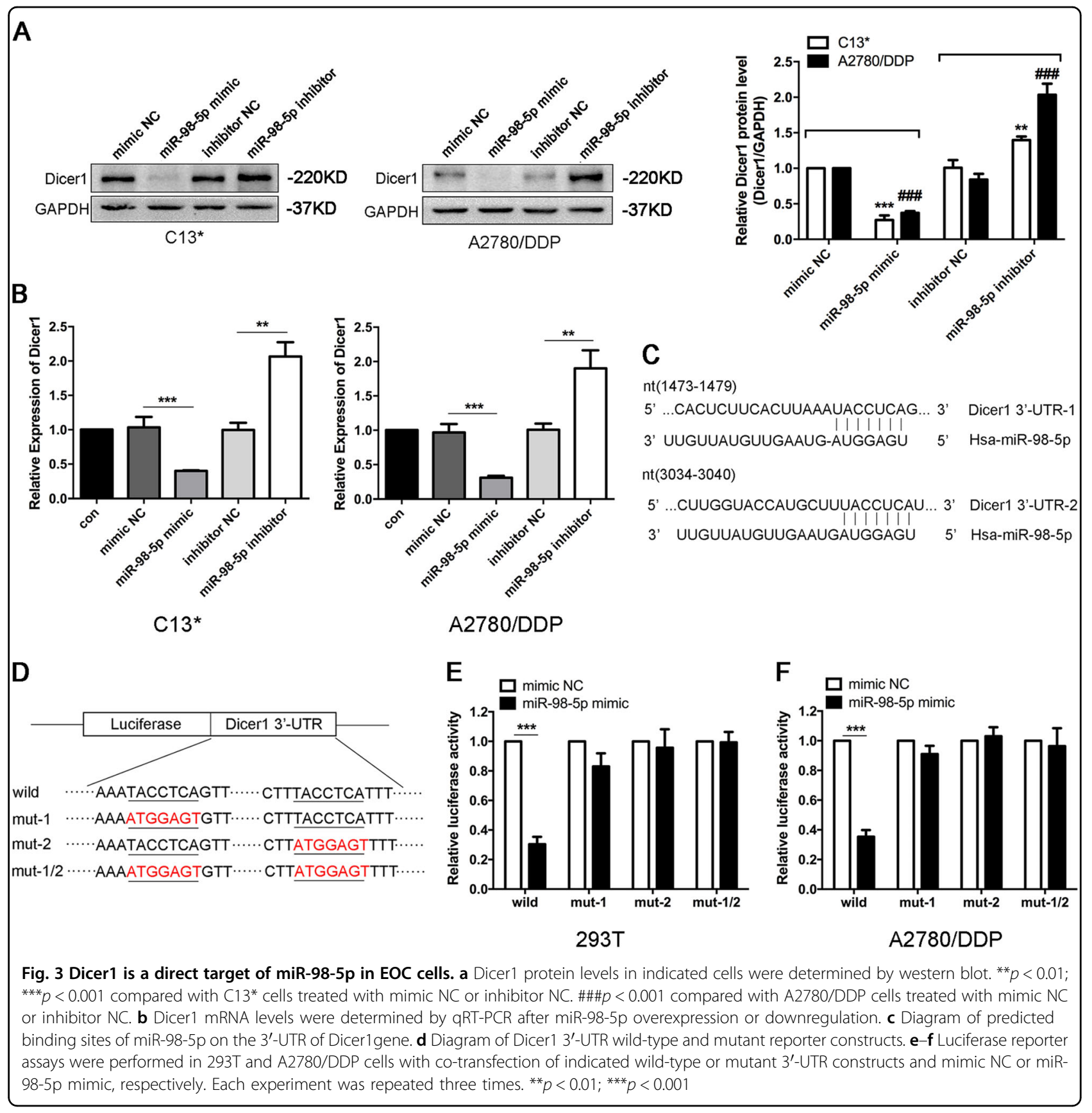

displayed a decreased proliferation percentage of Ki-67 positive tumor cells compared with the control group (Fig. 5g). Taken together, these results demonstrated the reversion of cisplatin resistance by ectopic miR-152 expression in vivo.

miR-152 expression is decreased in EOC, and miR-152 directly targets the $3^{\prime}$-UTR of RAD51 to decrease RAD51 expression

Subsequently, we detected the expression level of miR152 in clinical tissues, and found that the expression of
miR-152 was significantly weaker in EOC tissues than in normal tissues (Fig. 6a), and high miR-152 expression predicted better OS (Fig. 6b). This was consistant with the effect of miR-152 in turning around cisplatin resistance in EOC cells.

Next, we examined the mechanism by which miR-152 promote cisplatin sensitivity in EOC cells. With online prediction programs, we focused on RAD51, a central gene in homologous recombination (HR), which played a critical role in promoting strand transfer to resynthesize the damaged region ${ }^{24}$. Accordingly, we hypothesized that 


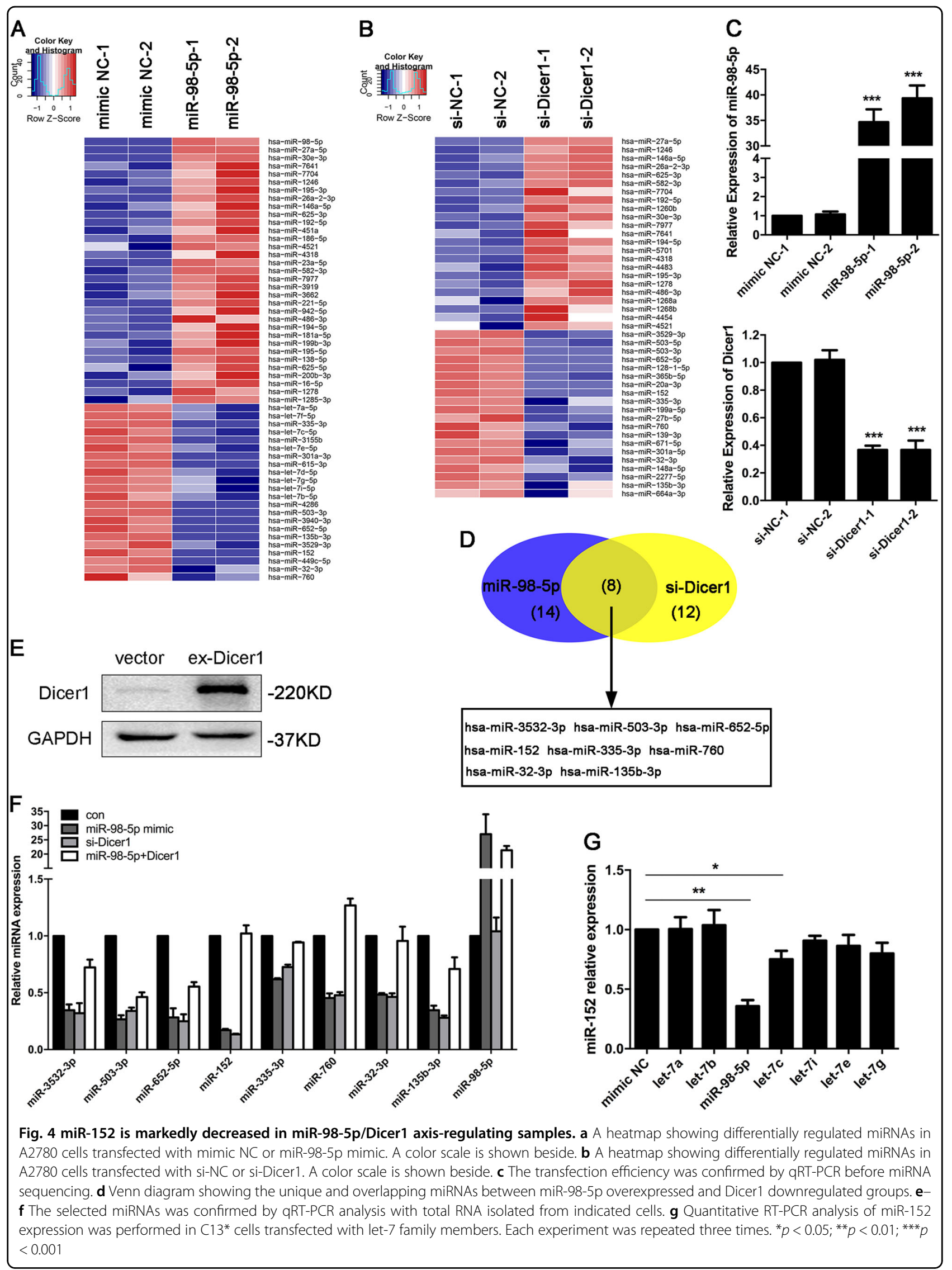




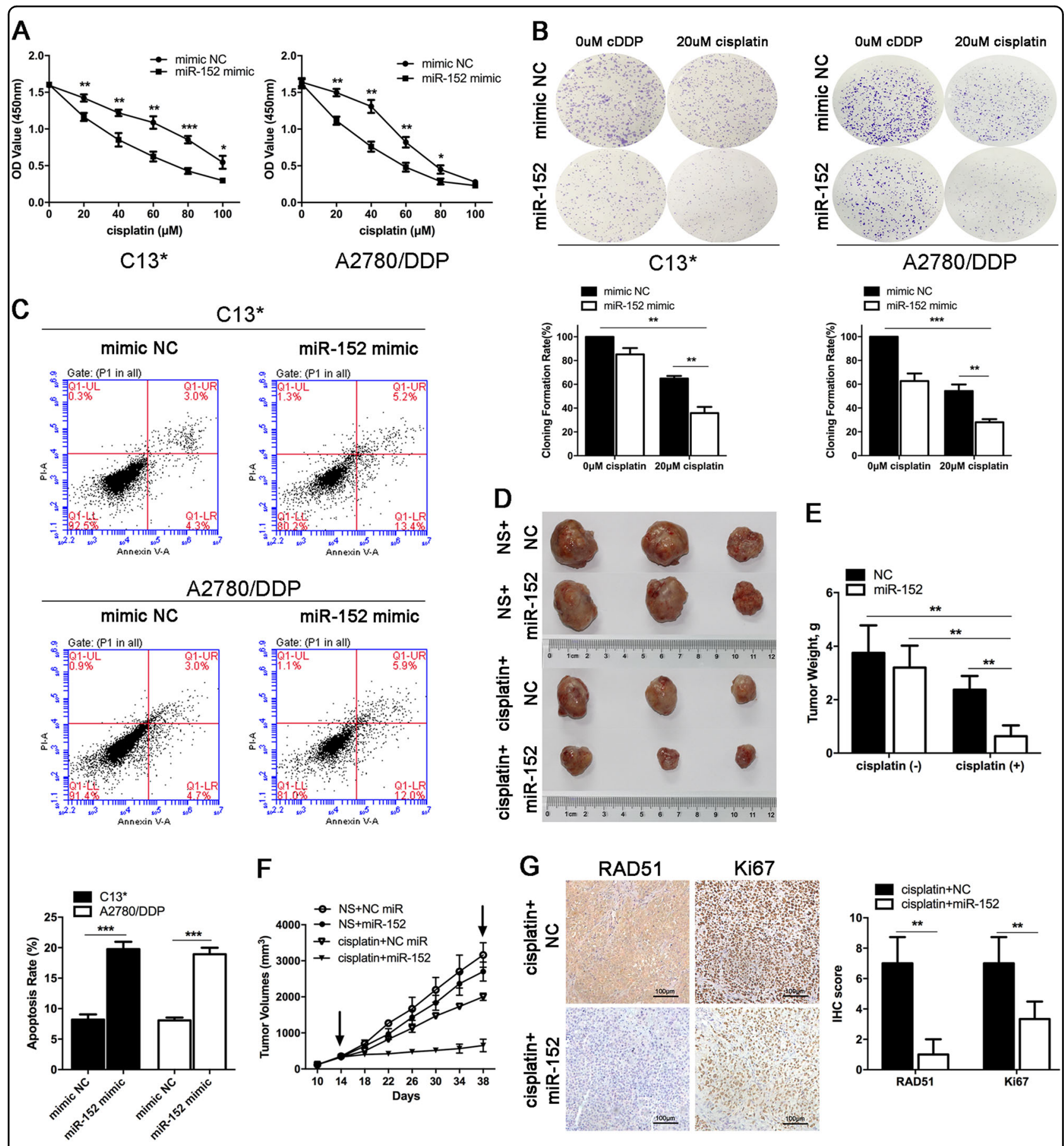

Fig. 5 Effects of miR-152 on cisplatin sensitivity of EOC cells in vitro and in vivo. a C13* and A2780/DDP cells were transfected with mimic NC or miR-152 for $24 \mathrm{~h}$, and then cell viability was assayed after treatment with increasing concentrations of cisplatin for $48 \mathrm{~h}$ by CCK-8 assay. $\mathbf{b}$ Colony formation of $\mathrm{C} 13^{*}$ and A2780/DDP cells transfected with mimic NC or miR-152 mimic after exposure to cisplatin (20 $\left.\mu \mathrm{M}\right) \mathbf{c}$ C13* and A2780/DDP cells transfected with mimic NC or miR-152 mimic were exposed to cisplatin $(20 \mu \mathrm{M})$ for $48 \mathrm{~h}$, and then the apoptotic cells were detected by flow cytometry. $\mathbf{d}$ The gross morphology of A2780/DDP cells subcutaneous xenograft tumors treated with NS plus agomiR-NC, NS plus agomiR-152, cisplatin plus agomiR-NC, or cisplatin plus agomiR-152 are shown. e Growth curves of xenograft tumors are shown. Tumor volumes were calculated as length $\times$ (square of width)/2. Arrows indicate the start and end of treatment, respectively. $\mathbf{f}$ The final xenograft tumor weights measured on day 38 after tumor cell injection. $\mathbf{g}$ The immunohistochemistry analyses for RAD51 and Ki67 were carried out on A2780/DDP xenograft tumor sections collected from mice with the indicated treatments. Representative staining are shown. Scale bars, $100 \mu \mathrm{m} .{ }^{*} p<0.05 ;{ }^{* *} p<0.01 ;{ }^{* * *} p<0.001$ 


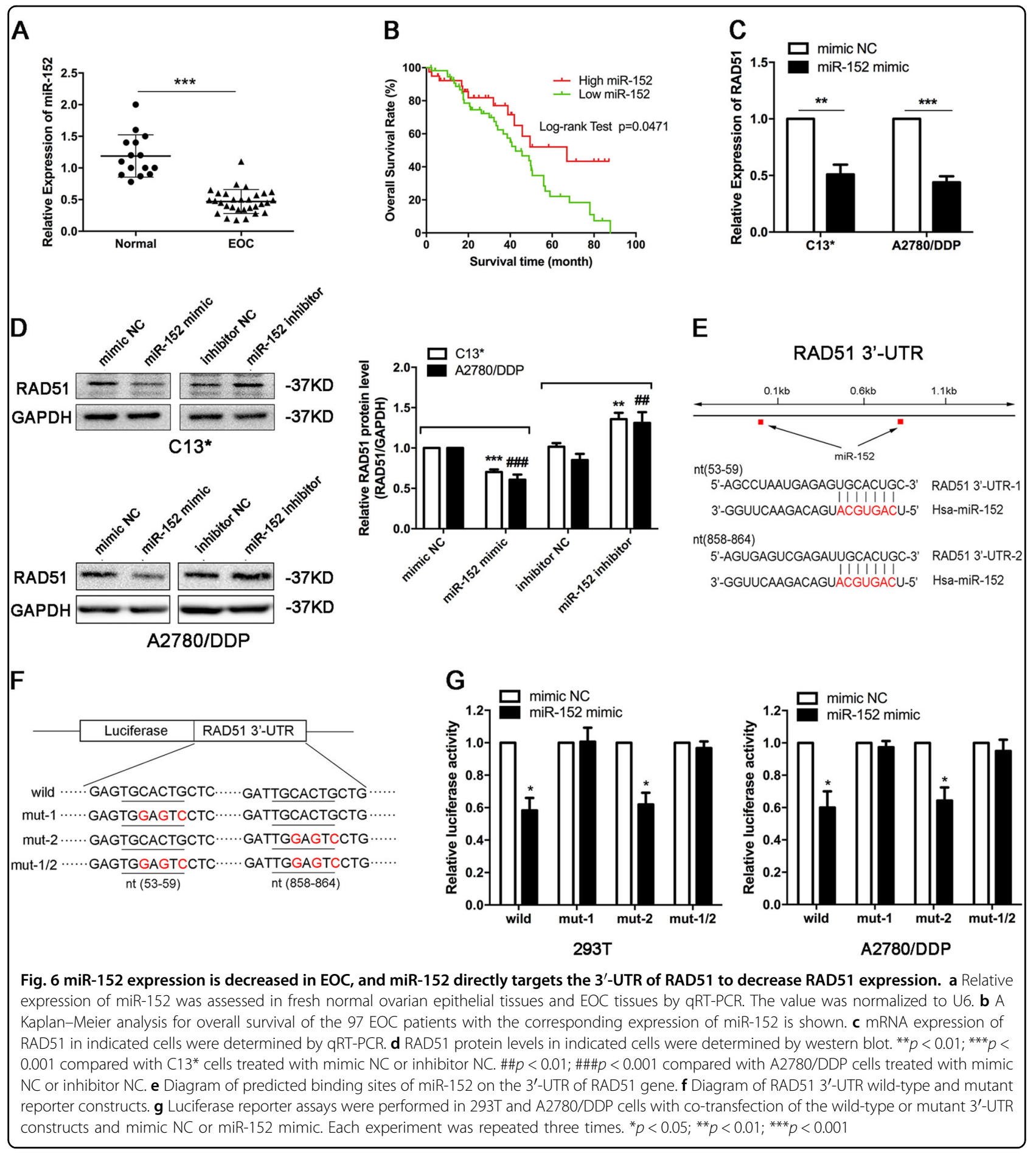

RAD51 may serve as a biologically relevant target of miR152 and participate in miR-152-mediated regulation of chemo-resistance in EOC. In support of this concept, we transfected miR-152 mimic in EOC cells and found that the protein and mRNA levels of RAD51 were both significantly reduced compared with the control cells (Fig. 6c, d). Furthermore, two putative binding sites were identified within 3'-UTR of RAD51 and demonstrated as complementary to the seed sequences of the miR-152 gene (Fig. 6e). Indeed, the ectopic expression of miR-152 in 293T and A2780/DDP cells significantly repressed the luciferase activity of construct carrying the wild-type $3^{\prime}$ UTR sequence of RAD51 (Fig. 6f). Luciferase activity was also decreased when the binding site 2 was mutated, 


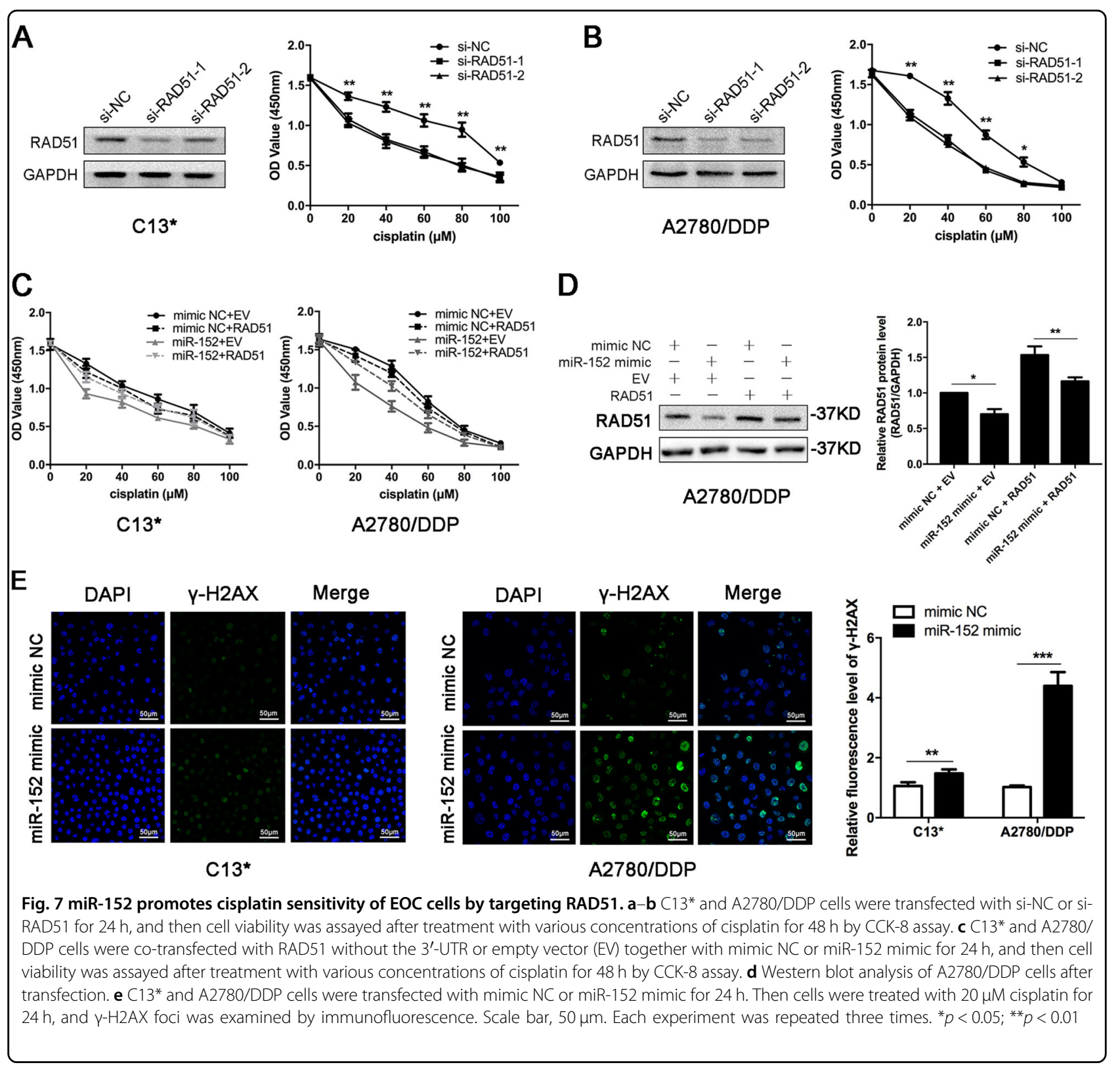

whereas mutation of the binding site 1 nearly rescued the decrease (Fig. 6g). These data suggest that miR-152 directly regulate RAD51 expression through its binding to site 1 (nt53-59) in the 3'-UTR of RAD51.

miR-152 promotes the cisplatin sensitivity of EOC cells by targeting RAD51

As RAD51 is an important protein in HR, knockdown of RAD51 could decrease DNA repair and increase sensitivity to DNA-damaging drugs, including cisplatin ${ }^{25}$. We further examined whether RAD51 suppression is critical for miR-152-induced cellular sensitivity to cisplatin in EOC cells. Remarkably, silencing RAD51 via small interfering RNAs (siRNA) statistically significantly sensitized
C13* and A2780/DDP cells to cisplatin, similar to miR152 mimic transfection (Fig. 7a, b). Moreover, the effect of miR-152 on cisplatin sensitivity was fully antagonized by the overexpression of RAD51 (by virtue of lacking the $3^{\prime}$ UTR), suggesting that miR-152-mediated sensitivity to cisplatin is primarily a result of RAD51 expression suppression (Fig. 7c, d).

Phosphorylated histone family member X ( $\gamma-\mathrm{H} 2 \mathrm{AX})$, a key component in DNA repair, forms nuclear foci at sites of DNA damage and creates a focus for accumulation of members involved in DNA repair ${ }^{26,27}$. The $\gamma$-H2AX foci detected by IF were significantly higher in miR-152 transfected cells than the control cells after treating with cisplatin for $24 \mathrm{~h}$ (Fig. 7e). 


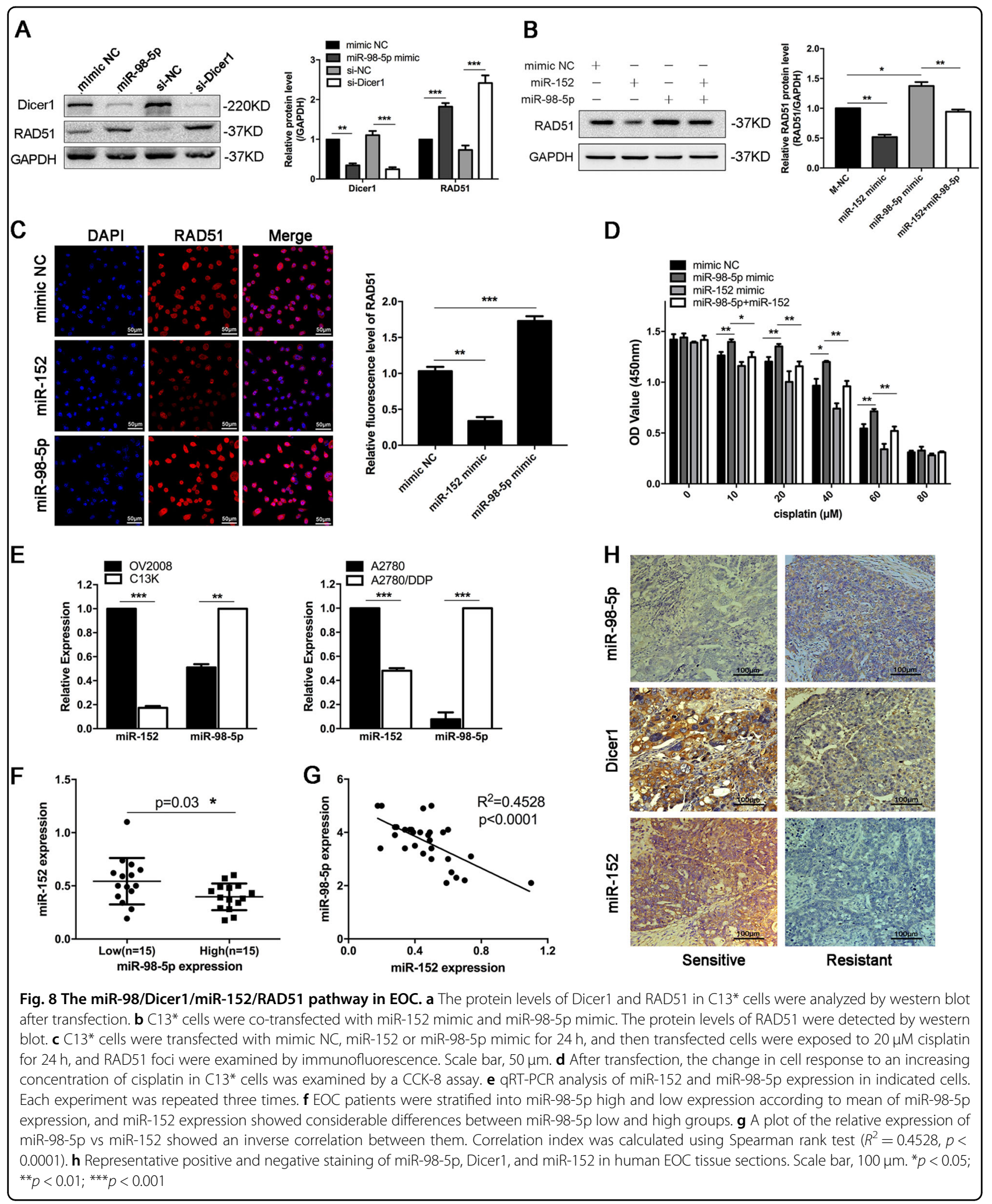

These data confirmed that miR-152 regulated cisplatin sensitivity of EOC cells by targeting RAD51 and led to defects in HR.
The miR-98-5p/Dicer1/miR-152/RAD51 pathway in EOC

Rad51 is involved in HR repair, and relocalized in the nucleus in response to DNA damage. Therefore, the 


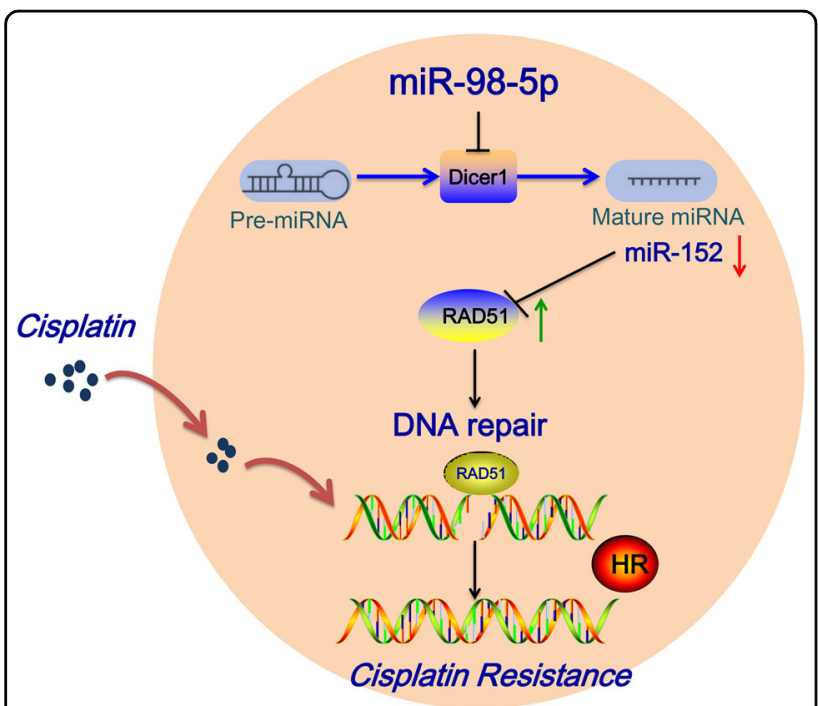

Fig. 9 The proposed working mode for the miR-98-5p-Dicer1miR-152 pathway of chemo-resistance control in ovarian cancer.

quantification of RAD51 foci could serve as a marker of HR. As shown in Fig. 8a, the upregulation of miR-98-5p or knockdown of Dicer1 significantly increased the expression of RAD51. However, miR-152 inhibited RAD51 expression in A2780/DDP cells, and upregulation of miR-152 abolished the ability of miR-98-5p to upregulate RAD51 level (Fig. 8b). The change of protein expression of RAD51 was further confirmed by immunofluorescence (Fig. 8c). In addition, to further study the roles of miR-152 in miR-98-5p-mediated cisplatin resistance, we co-transfected miR-98-5p mimic and miR-152 mimic in A2780 cells and found that miR-152 reexpression attenuated miR-98-5p-induced cell resistance to cisplatin by a CCK- 8 assay (Fig. $8 \mathrm{~d}$ ). These results indicate that miR-152 functions as a mediator of miR-985p-induced RAD51 upregulation.

Next, we evaluated the expression relevance of miR-98$5 \mathrm{p}$ and miR-152 in EOC cells and tissues. The results revealed that miR-152 was significantly downregulated in cisplatin-resistant $\mathrm{C} 13^{*}$ and A2780/DDP cells, but miR98-5p was overexpressed in C13* and A2780/DDP cells (Fig. 8e). Meanwhile, the protein level of RAD51 was lower in OV2008 and A2780 cells compared with C13* and A2780/DDP cells, which was consistant with their sensitivity to cisplatin (Supplementary Figure 5A). In addition, using Spearman's correlation analysis, a negative correlation, with $R^{2}=0.4528$, was observed between miR98-5p and miR-152 $(p<0.0001)$, suggesting the existence of miR-98-5p-dependent regulation of miR-152 (Fig. 7f, g). Moreover, representative positive and negative staining of miR-98-5p, Dicer1, and miR-152 in human EOC tissue sections is shown in Fig. 8h. Furthermore, we performed a negative experiment to assess if miR-98-5p has effect on cisplatin response of COV362 cells with BRCA1 mutation. The results indicated COV362 cells treated with miR-98$5 \mathrm{p}$ mimic caused no obvious change in cisplatin response compared with the control cells (Supplementary Figure $5 \mathrm{~B}$ ), providing further evidence that high miR-98-5p expression causes cisplatin resistance via RAD51, a central member in HR.

In conclusion, these results unveil a novel pathway driving chemo-resistance to cisplatin in EOC cells, where miR-98-5p inhibition of Dicer1 reduces the levels of miR152, which binds to the $3^{\prime}$-UTR of RAD51 and enhances RAD51 expression, resulting in elevated HR efficiency (Fig. 9).

\section{Discussion}

In clinical situations, acquired drug resistance frequently follows chemotherapeutic regimens and is considered the major cause of mortality in $\mathrm{EOC}^{28}$. Although cisplatin could cause intra-strand DNA crosslinks and is the first-line chemotherapy drug for ovarian cancer, drug resistance leading to chemotherapy failure is almost unavoidable. Increasing studies have suggested that miRNA is a new class of therapy molecule, and has a more modulatory role than traditional drugs.

A large body of evidence suggests that the global downregulation of miRNA expression is a widespread phenomenon in cancer ${ }^{7,29,30}$. The underlying mechanisms of miRNA dysregulation has not been fully illustrated or summarized. Epigenetic modifications, such as methylation, could directly modulate miRNA expression ${ }^{31}$. Additionally, transcription factors have been reported to play important roles in regulating miRNAs. For instance, transcription factor nrf2-regulated miR-1 and miR-206 to drive tumourigenesis ${ }^{32}$. Moreover, the regulation of miRNA processing factors also subsequently impacted miRNA expression and caused biological transformations in cancer. For example, Grazinao et al. identified that the miR-103/107 family inhibited the expression of Dicer, causing global miRNA downregulation and metastasis and poor outcome in breast cancer patients ${ }^{33}$.

The let-7 family has been known as one of the earliest miRNAs to be identified. It has been reported that let-7 could directly bind to the 3'-UTR of Dicer, and play a role in tuning of the mature miRNA expression and carcinogenesis. In the present study, the mechanism underlying the effects of miR-98-5p, a member of let-7 family, was explored in EOC. The upregulation of miR-98-5p was identified in EOC samples, and patients with high miR98-5p expression had a significantly poorer prognosis than those with low miR-98-5p. We found that miR-98-5p could promote cisplatin resistance in EOC cells. Furthermore, our study demonstrated that miR-98-5p could bind to the 3'-UTR of Dicer1 and reduce the expression of 
Dicer1, which has been reported to associate with resistance to chemotherapy and poor clinical outcomes ${ }^{9,34}$. Then, we defined the identity of key miRNAs acting as the downstream mediators of the miR-98-5p/Dicer axis.

By miRNA sequencing, we screened out a subset of miRNAs downstream of the miR-98-5p/Dicer1 axis. We then focused on miR-152, because it was reduced most efficiently and previous studies have shown that this molecule displayed properties opposite of miR-98-5p in our study: miR-152 is downregulated in cisplatin-resistant EOC cells and contributes to cisplatin sensitivity in $E C^{20}$. Subsequently, the role of miR-152 in regulating EOC chemo-resistance was further confirmed by demonstrating RAD51 as a direct target of miR-152 and validating that miR-152 could induce defects in DNA repair and promote drug sensitivity to cisplatin in vitro and in vivo. HR is involved in tumor chemo-resistance, and RAD51 plays a primary role in this pathway. Indeed, dysregulation of RAD51 can sensitize tumor cells to DNA-damaging drugs, including cisplatin ${ }^{25,35,36}$. In addition, we disclosed miR-98-5p and miR-152 relevance in EOC, and concluded that miR-98/miR-152 relationship is a key player in the drug resistance of EOC cells.

However, it should be pointed out that the role of miR98 in cancer is still controversial depending on the tumor type. Several studies have indicated that miR-98 serve as tumor suppressor, but the function of miR-98 is tumortype specific. miR-98-5p was found to be downregulated in various cancer types ${ }^{14,15}$. Moreover, reduced miR-98$5 p$ levels have also been implicated in resistance to cisplatin and radiotherapy, and the overexpression of miR98-5p could promote chemosensitivity in lung adenocarcinoma ${ }^{37}$ and increase radio-sensitivity in esophageal squamous cell carcinoma ${ }^{38}$. However, miR-98 was also found to be upregulated in primary breast cancer specimens confirmed by real-time PCR and microarrays ${ }^{16}$, and expressed at higher levels in small cell lung cancer cell lines than in immortalized human bronchial epithelial cells ${ }^{17}$. These controversial observations indicate that the complexity of miRNAs and the function of specific miRNA differ markedly depend on tumor types.

The present study has several limitations. Although we observed that miR-98-5p could promote chemoresistance to cisplatin in EOC cells, it might be better to use an in vivo model to further evaluate its effects. In addition, we could not address the question of why miR98-5p and miR-103/107 regulate different downstream activities by targeting Dicer1 and display different functions in cancer. Other biological processes should be further explored.

This study focuses on miR-98-5p because it showed the greatest suppression effect on Dicer1 among the let-7 family and it was markedly upregulated in cisplatinresistant EOC cells. Growing evidence suggests that the let-7 family plays a vital role in tumor suppression through repressing cell proliferation, invasion, metastasis, and resistance to therapy in lung cancer ${ }^{39}$, prostate can$\operatorname{cer}^{40}$, and hepatocellular carcinoma ${ }^{41}$. In the present study, we found that miR-152 is remarkably downregulated by miR-98-5p compared with other members of the let-7 family in EOC cells. This finding may explain the obviously different function of miR-98-5p from the let-7 family in EOC.

In conclusion, to our knowledge, we showed for the first time that miR-98-5p was upregulated in EOC samples, and miR-98-5p promoted chemo-resistance to cisplatin through a novel miR-98-5p/Dicer1/miR-152 pathway. In addition, our study showed that high miR-152 expression statistically significantly sensitized EOC cells to cisplatin in vitro and in vivo. These results may provide novel predictive and prognostic factors for EOC and the design of novel miRNA-based therapeutic strategies against EOC.

\section{Materials and Methods \\ Cell culture and miRNA transfection}

The human ovarian cancer cell lines C13*, OV2008, A2780, and its cisplatin-resistant cell line A2780/DDP were purchased from the American Type Culture Collection (Manassas, VA, USA). HO8910, SKOV3, CaOV3, Hey, COV362, and the immortalized ovarian epithelial cell line (Moody) were conserved in our laboratory. All cell lines were cultured in Dulbecco's modified Eagle's medium (Gibco, Auckland, New Zealand) supplemented with $10 \%$ fetal bovine serum and $1 \%$ penicillin/streptomycin in a humidified atmosphere of $5 \% \mathrm{CO}_{2}$ at $37^{\circ} \mathrm{C}$. MiRNA mimic, inhibitor, and the negative controls were purchased from RiboBio (Guangzhou, China) and transfected into EOC cells with Lipofectamine 3000 (Life Technologies, Carlsbad, CA, USA) according to the manufacturer's instructions.

\section{Gene silence and plasmid transfection}

The Dicer1 and RAD51 siRNA were designed and synthesized by RiboBio (Guangzhou, China) to knock down the Dicer1 and RAD51, respectively. The target sequences are as follows: siDicer1: TGCTTGAAGCAGCTCTGGA and siRAD51: GACTGCCAGGATAAAGCTT. The Dicer1 plasmid and RAD51 plasmid (Table 2) were purchased from Qihe Biotechnology (Shanghai, China). The cells were transfected with siRNA or plasmid using Lipofectamine 3000 (Life Technologies), following the manufacturer's protocol.

\section{EOC tissue samples}

For formalin-fixed, paraffin-embedded samples, 30 normal ovarian tissues, 10 borderline tissues, and 97 EOC tissues were collected from patients at Shanghai Jiao Tong 
Table 2 Cloning primers used in this study

\begin{tabular}{ll}
\hline Cloning primers & Sequence \\
\hline DICER1 3'-UTR sense & 5'-GGCGGCTCGAGGACTTGTAGGCACTCTTCAC-3' \\
DICER1 3'-UTR anti-sense & 5'-AATGCGGCCGCGCAGGGTATCAGAATCTIT-3' \\
DICER1-mut-1 3'-UTR sense & 5'-GGCGGCTCGAGGACTTGTAGGCACTCTTCAC-3' \\
DICER1-mut-1 3'-UTR anti-sense & 5'-TTAAAATGGAGTGTTCTTCTTाTCTITGC-3' \\
DICER1-mut-2 3'-UTR sense & 5'-CCATGCTTATGGAGTTTTCAAGAAAATATGCTT-3' \\
DICER1-mut-2 3'-UTR anti-sense & 5'-TCTTGAAAACTCCATAAGCATGGTACCAAGTGC-3' \\
RAD51 3'-UTR sense & 5'-AATTCTAGGCGATCGCTCGAGCGCCATTAATGCAGATGGAGT-3' \\
RAD51 3'-UTR anti-sense & 5'-ATTTTATTGCGGCCAGCGGCCGCCTCACTCTGTCACCCTGGCT-3' \\
RAD51-mut-1 3'-UTR sense & 5'-TAAGTGCTGCAGCCTAATGAGAGTGGAGTCCTCCCTGGGGTCTCTACAGGCCTC-3' \\
RAD51-mut-1 3'-UTR anti-sense & 5'-GAGGCCTGTAGAGAACCCCAGGGAGGACTCCACTCTCATTAGGCTGCAGCACTTA \\
RAD51-mut-2 3'-UTR sense & 5'-GTGGAAGTTGCAGTGAGTCGAGATTGGAGTCCTGCATTCCAGCCAGGGTGACAGAGT-3' \\
RAD51-mut-2 3'-UTR anti-sense & 5'-ACTCTGTCACCCTGGCTGGAATGCAGGACTCCAATCTCGACTCACTGCAACTTCCAC-3' \\
PCDNA-Dicer1 sense & ATGAAAAGCCCTGCTTGGCAAC \\
PCDNA-Dicer1 anti-sense & CCTCAGGTTCCCAATAGCTGA \\
PCDNA-RAD51 sense & ATGGCAATGCAGATGCAGCTT \\
PCDNA-RAD51 anti-sense & AGTGGGAGATGCCAAAGACTGA \\
\hline
\end{tabular}

University Affiliated Shanghai General Hospital between 2004 and 2016. All patients were treated with standard care of platinum-based therapy after surgery, and the informed consent was obtained from all patients. Platinum sensitivity or platinum resistance was defined as relapse or progression within 6 months or after 6 months from the last chemotherapy, respectively. Primary therapy response was defined as the response evaluation criteria in solid tumors. We obtained ethical approval and support from the Institutional Research Ethics Committee of Shanghai Jiao Tong University Affiliated Shanghai General Hospital.

For fresh tissues, 15 normal ovarian tissues and 30 EOC tissues were gathered between June, 2014 and September, 2015 , and stored at $-80^{\circ} \mathrm{C}$. The tumor content of the tissues was examined by haematoxylin and eosin staining in the pathology units. Only specimens containing more than $60 \%$ of tumor tissue were used in this study.

\section{Quantitative real-time PCR}

Total RNA from tumor samples or cell lines was extracted using TRIzol reagent (TaKaRa, Dalian, China). Complementary DNA was synthesized with random primers or miRNA specific stem-loop primers (RiboBio) using a PrimeScript RT reagent kit (TaKaRa). Subsequently, qRT-PCR was performed with SYBR Premix Ex Taq (TaKaRa) on a 7500 real-time PCR system (AB Applied Biosystems, Mannheim, Germany). The $2^{-\Delta \Delta C t}$ method was applied to calculate the relative expression
Table 3 qRT-PCR Primers used in this study

\begin{tabular}{ll}
\hline qRT-PCR Primers & Sequences \\
\hline GAPDH sense & 5'-GAAATCCCATCACCATCTTCCAGG-3' \\
GAPDH anti-sense & 5'-GAGCCCCAGCCTTCTCCATG-3' \\
DICER1 sense & 5'-GAGCTGTCCTATCAGATCAGGG-3' \\
DICER1 anti-sense & 5'-ACTTGTTAGCAACCTGGTT-3' \\
RAD51 sense & 5'-CAACCCATTTCACGGTTAGAGC-3' \\
RAD51 anti-sense & 5'-TTCTTGGCGCATAGGCAACA-3' \\
\hline
\end{tabular}

levels using GAPDH or U6 as the endogenous control. The mRNA primer sequences are listed in Table 3.

\section{Western blotting}

Equal amounts of cellular protein extracts were separated on SDS-polyacrylamide mini-gels and transferred onto a PVDF membrane (Millipore, Billerica, MA, USA) at $350 \mathrm{~mA}$ for $1.5 \mathrm{~h}$. The membranes were blocked with 5\% BSA (Roche, Mannheim, Germany) for $1 \mathrm{~h}$, and then incubated with the appropriate primary antibody overnight at $4{ }^{\circ} \mathrm{C}$. Antibodies against human RAD51, Dicer1 were purchased from Abcam Inc. Antibodies against GAPDH was purchased from Cell Signaling Technology, Inc. After washing with Tris-buffered saline with Tween20 (TBST) three times, the membranes were incubated with secondary antibody for $1 \mathrm{~h}$ at room temperature. The 
proteins were visualized using ECL chemiluminescence (Millipore), and quantified with ImageJ (National Institutes of Health, Bethesda, MD, USA).

\section{Colony formation assay}

Twenty-four hours after transiently transfecting with miR-152, miR-NC, si-RAD51, or si-NC, the cells were harvested. The cells were seeded onto six-well plates at a density of 800 cells per well, treated with or without $20 \mu \mathrm{M}$ cisplatin for $48 \mathrm{~h}$, and then recovered for 10 days in fresh DMEM containing 10\% FBS. The cells were fixed in methanol and stained with $0.1 \%$ crystal violet. The samples were photographed and the numbers of visible colonies that contained $>50$ cells were counted.

\section{In situ hybridization and scoring}

The expression of miRNA in paraffin-embedded tissue specimens was determined by an in situ hybridization kit (MK1030, Boster, Wuhan, China). Briefly, 6-um-thick sections of paraffin-embedded specimens were deparaffinized with xylene and rehydrated in a series of ethanol. After Proteinase- $\mathrm{K}$ incubation for $15 \mathrm{~min}$ at $37^{\circ} \mathrm{C}$, the slides were prehybridized in a hybridization solution at 37 ${ }^{\circ} \mathrm{C}$ for $2 \mathrm{~h}$. Then, tissue sections were hybridized with $5^{\prime}$ digoxigenin-labeled (DIG-labelled) oligonucleotide probe at $37^{\circ} \mathrm{C}$ overnight. After stringent washes with $5 \times \mathrm{SSC}$, $1 \times$ SSC, and $0.2 \times$ SSC buffers, the sections were blocked with DIG blocking buffer at $37^{\circ} \mathrm{C}$ for $30 \mathrm{~min}$. An anti-DIG antibody was applied, and the sections were incubated at $37^{\circ} \mathrm{C}$ for $1 \mathrm{~h}$. After washing in a staining solution, the sections were developed by diaminobenzidine-hydrogen peroxide. Scoring was measured by the cell cytoplasm staining. The sections were evaluated based on the percentage of positively stained cells $(0-3)$ and the intensity of staining (0-3). Then, the score of miRNA expression was calculated as percentage $\times$ intensity of the staining. Therefore, score 0 presents negative (-), 1-2 as weak positive, $(+), 3-4$ as moderate positive $(++)$, and $6-9$ as strong positive $(+++)$. Scoring with ' - ' and ' + ' was regarded as lower miR-98-5p expression, whereas ' ++ ' and ' +++ ' represented higher expression of miR-98-5p.

\section{Cell immunofluorescence staining}

Cells were grown on coverslips and exposed to $20 \mu \mathrm{M}$ cisplatin for $24 \mathrm{~h}$. After treatment, the cells were fixed with $4 \%$ paraformaldehyde for $20 \mathrm{~min}$, blocked with $5 \%$ bovine serum albumin containing $0.2 \%$ Triton X-100 for $30 \mathrm{~min}$, and incubated with antibodies against RAD51 (1:200, Abcam) or $\gamma$-H2AX (1:200, Cell Signaling Technology) overnight at $4{ }^{\circ} \mathrm{C}$. Then, the cells were incubated with relative secondary antibodies conjugated to fluorescein isothiocyanate (1:100, Molecular Probes, Invitrogen, USA) for $1 \mathrm{~h}$ at room temperature. Nuclei were counterstained with 4'6-diamidino-2-phenylindole
(DAPI) for $5 \mathrm{~min}$. The fluorescence images were captured with laser-scanning confocal microscopy (Leica, Heidelberg, Germany).

\section{Apoptosis assay}

For the assessment of apoptosis, the cells were collected and stained with the Annexin V Apoptosis Detection kit APC (eBioscience, San Diego, CA, USA). The flow cytometry events were conducted on the FACSCalibur flow cytometer. The data for apoptosis were analyzed with FlowJo (Tree Star, Ashland, OR, USA).

\section{Luciferase reporter assay}

The 3'-UTR of RAD51 containing the wild-type or mutated binding sites of miR-152 were amplified with PCR method (Table 2). We generated four Luc-RAD51 3'-UTR constructs, including one wild-type binding sequence and three mutated binding sequences. All the constructs containing $3^{\prime}$-UTR inserts were sequenced and verified. The Luciferase assay was performed in $293 \mathrm{~T}$ and A2780/DDP cell lines. Cells were seeded into 24-well plates in triplicate. After $24 \mathrm{~h}$, the cells were transfected with RAD51 reporter constructs and miR-152 mimic, or miR-NC using Lipofectamine 3000 (Invitrogen). Luciferase activity was measured in cell lysates $24 \mathrm{~h}$ after transfection using a Dual Luciferase Reporter System (Promega, Madison, WI, USA).

\section{Chemosensitivity assay}

Cisplatin was puechased from Sigma-Aldrich, US. Logarithmically growing cells were transfected with 50 nM miRNA mimics/inhibitors or miR NC, and then seeded onto 96-well plates at $1 \times 10^{4}$ cells/well at $24 \mathrm{~h}$ later. After incubating in medium containing various concentration of cisplatin for $48 \mathrm{~h}$, cell viability was estimated by the CCK- 8 reagent (Dojindo, Kumamoto, Japan) at $450 \mathrm{~nm}$ using a Model 550 series microplate reader (Bio-Rad Laboratories). The assay was performed with three replicates. The $\mathrm{IC}_{50}$ values were then calculated.

\section{Tumor xenograft model}

All of the animal experiments were performed in strict accordance with the Guide for the Care and Use of Laboratory Animals, and approved by the Department of Laboratory Animal Science at Shanghai Jiao Tong University School of Medicine. A total of 12 BALB/C female athymic mice at 4 weeks of age were housed and maintained in specific pathogen-free conditions. We subcutaneously injected $8 \times 10^{6}$ A278/DDP cells resuspended in $100 \mu \mathrm{L}$ of phosphate-buffered saline into the ambilateral flank of mice. 10 days later, the mice were randomly assigned into two groups with 6 mice per group. AgomiR-9 and agomiR-NC (RiboBio) were directly injected into the left and right flank tumor of the 12 mice, 
respectively, at a dose of $5 \mathrm{nmol}$ (diluted in $50 \mu \mathrm{L}$ phosphate-buffered saline) per mouse every 4 days for 8 times. After 4 days, the mice in the experiment group were treated with cisplatin at a dose of $5 \mathrm{mg} / \mathrm{kg}$ intraperitoneally every 4 days for 7 times, and the control group mice were injected with normal saline. After the initial treatment, the tumor size was assessed every 4 days by a digital caliper, and tumor volume was calculated as length $\times$ (square of width)/ 2 . The mice were killed following cervical dislocation under anesthesia at 38 days after injection. The experiments were performed in an observer-blinded and randomized manner.

\section{Statistical analysis}

All data are presented as the means $\pm \mathrm{SD}$. Two-tailed Student's $t$-test was used to compare the two groups. Survival curves were examined by Kaplan-Meier analysis with the log-rank test analysis. Spearman's nonparametric correlation test was performed to examine the correlation between expression levels of miR-98-5p and miR-152 by GraphPad Prism 5.0 (GraphPad Software, Inc., La Jolla, CA, USA). All statistical analyses were performed using SPSS 20.0. $P$-value $<0.05$ was considered statistically significant.

\section{Acknowledgements}

This work was supported by The National Key Research and Development Program of China (2016YFC 130299), and the National Natural Science Foundation of China (NSFC 81201541).

\section{Conflict of interest}

The authors declare that they have no conflict of interest.

\section{Publisher's note}

Springer Nature remains neutral with regard to jurisdictional claims in published maps and institutional affiliations.

Supplementary Information accompanies this paper at (https://doi.org/ 10.1038/s41419-018-0390-7).

Received: 22 November 2017 Revised: 5 February 2018 Accepted: 6 February 2018

Published online: 18 April 2018

\section{References}

1. Jemal, A. et al. Global cancer statistics. Ca. Cancer J. Clin. 61, 69-90 (2011).

2. Cho, K. R. \& Shih, Ie,M. Ovarian cancer. Annu. Rev. Pathol. 4, 287-313 (2009).

3. Miller, D. S. et al. Phase II evaluation of pemetrexed in the treatment of recurrent or persistent platinum-resistant ovarian or primary peritoneal carcinoma: a study of the Gynecologic Oncology Group. J. Clin. Oncol. 27, 2686-2691 (2009).

4. Bushati, N. \& Cohen, S. M. microRNA functions. Annu. Rev. Cell Dev. Biol. 23, 175-205 (2007).

5. Filipowicz, W., Bhattacharyya, S. N. \& Sonenberg, N. Mechanisms of posttranscriptional regulation by microRNAs: are the answers in sight? Nat. Rev. Genet. 9, 102-114 (2008).

6. Zhang, B., Wang, Q. \& Pan, X. MicroRNAs and their regulatory roles in animals and plants. J. Cell. Physiol. 210, 279-289 (2007)
7. $L u$, J. et al. MicroRNA expression profiles classify human cancers. Nature $\mathbf{4 3 5}$, 834-838 (2005).

8. Thomson, J. M. et al. Extensive post-transcriptional regulation of microRNAs and its implications for cancer. Genes Dev. 20, 2202-2207 (2006).

9. Merritt, W. M. et al. Dicer, Drosha, and outcomes in patients with ovarian cancer. N. Engl. J. Med. 359, 2641-2650 (2008).

10. Johnson, S. M. et al. RAS is regulated by the let-7 microRNA family. Cell 120, 635-647 (2005).

11. Sun, X. et al. The insights of Let-7 miRNAs in oncogenesis and stem cell potency. J. Cell. Mol. Med. 20, 1779-1788 (2016).

12. Boyerinas, B., Park, S. M., Hau, A., Murmann, A. E. \& Peter, M. E. The role of let-7 in cell differentiation and cancer. Endocr. Relat. Cancer 17, F19-F36 (2010).

13. Tokumaru, S., Suzuki, M., Yamada, H., Nagino, M. \& Takahashi, T. let-7 regulates Dicer expression and constitutes a negative feedback loop. Carcinogenesis 29, 2073-2077 (2008)

14. Alajez, N. M. et al. Enhancer of Zeste homolog 2 (EZH2) is overexpressed in recurrent nasopharyngeal carcinoma and is regulated by miR-26a, miR-101, and miR-98. Cell Death Dis. 1, e85 (2010).

15. Panda, H., Chuang, T. D., Luo, X. \& Chegini, N. Endometrial miR-181a and miR98 expression is altered during transition from normal into cancerous state and target PGR, PGRMC1, CYP19A1, DDX3X, and TIMP3. J. Clin. Endocrinol. Metab. 97, E1316-E1326 (2012).

16. Yan, L. X. et al. MicroRNA miR-21 overexpression in human breast cancer is associated with advanced clinical stage, lymph node metastasis and patient poor prognosis. RNA 14, 2348-2360 (2008).

17. Du, L. et al. miR-93, miR-98, and miR-197 regulate expression of tumor suppressor gene FUS1. Mol. Cancer Res. 7, 1234-1243 (2009).

18. Kuang, Y. et al. Repression of Dicer is associated with invasive phenotype and chemoresistance in ovarian cancer. Oncol. Lett. 5, 1149-1154 (2013).

19. Hendrickson, D. G. et al. Concordant regulation of translation and mRNA abundance for hundreds of targets of a human microRNA. PLOS Biol. 7, e1000238 (2009).

20. Xiang, Y. et al. MiR-152 and miR-185 co-contribute to ovarian cancer cells cisplatin sensitivity by targeting DNMT1 directly: a novel epigenetic therapy independent of decitabine. Oncogene 33, 378-386 (2014).

21. Huang, J., Wang, Y., Guo, Y. \& Sun, S. Down-regulated microRNA-152 induces aberrant DNA methylation in hepatitis B virus-related hepatocellular carcinoma by targeting DNA methyltransferase 1. Hepatology 52, 60-70 (2010).

22. $\mathrm{Xu}$, Q. et al. A regulatory circuit of miR-148a/152 and DNMT1 in modulating cell transformation and tumor angiogenesis through IGF-IR and IRS1. J. Mol. Cell Biol. 5, 3-13 (2013).

23. He, X. X. et al. MicroRNA-375 targets AEG-1 in hepatocellular carcinoma and suppresses liver cancer cell growth in vitro and in vivo. Oncogene 31, 3357-3369 (2012).

24. Daboussi, F., Dumay, A., Delacote, F. \& Lopez, B. S. DNA double-strand break repair signalling: the case of RAD51 post-translational regulation. Cell. Signal. 14, 969-975 (2002)

25. Yang, Z., Waldman, A. S. \& Wyatt, M. D. Expression and regulation of RAD51 mediate cellular responses to chemotherapeutics. Biochem. Pharmacol. $\mathbf{8 3}$ 741-746 (2012).

26. Firsanov, D. V., Solovjeva, L. V. \& Svetlova, M. P. H2AX phosphorylation at the sites of DNA double-strand breaks in cultivated mammalian cells and tissues. Clin. Epigenetics 2, 283-297 (2011).

27. Kinner, A., Wu, W., Staudt, C. \& lliakis, G. Gamma-H2AX in recognition and signaling of DNA double-strand breaks in the context of chromatin. Nucleic Acids Res. 36, 5678-5694 (2008).

28. Konecny, G. E. et al. Prognostic and therapeutic relevance of molecular subtypes in high-grade serous ovarian cancer. J. Natl. Cancer Inst. 106, pii: dju249 (2014).

29. Ozen, M., Creighton, C. J., Ozdemir, M. \& Ittmann, M. Widespread deregulation of microRNA expression in human prostate cancer. Oncogene 27, 1788-1793 (2008).

30. Ventura, A. \& Jacks, T. MicroRNAs and cancer: short RNAs go a long way. Cell 136, 586-591 (2009).

31. Hou, J. et al. Identification of miRNomes in human liver and hepatocellular carcinoma reveals miR-199a/b-3p as therapeutic target for hepatocellular carcinoma. Cancer Cell. 19, 232-243 (2011).

32. Singh, A. et al. Transcription factor NRF2 regulates miR-1 and miR-206 to drive tumorigenesis. J. Clin. Invest. 123, 2921-2934 (2013).

33. Martello, G. et al. A MicroRNA targeting dicer for metastasis control. Cell 141 1195-1207 (2010) 
34. Kawahara, K. et al. A low Dicer expression is associated with resistance to 5-FUbased chemoradiotherapy and a shorter overall survival in patients with oral squamous cell carcinoma. J. Oral. Pathol. Med. 43, 350-356 (2014).

35. Kiyohara, E., Tamai, K., Katayama, I. \& Kaneda, Y. The combination of chemotherapy with HVJ-E containing Rad51 siRNA elicited diverse anti-tumor effects and synergistically suppressed melanoma. Gene. Ther. 19, 734-741 (2012).

36. Tsai, M. S., Kuo, Y. H., Chiu, Y. F., Su, Y. C. \& Lin, Y. W. Down-regulation of Rad51 expression overcomes drug resistance to gemcitabine in human non-smallcell lung cancer cells. J. Pharmacol. Exp. Ther. 335, 830-840 (2010).

37. Xiang, Q. et al. MicroRNA-98 sensitizes cisplatin-resistant human lung adenocarcinoma cells by up-regulation of HMGA2. Pharmazie 68, 274-281 (2013).
38. Jin, Y. Y. et al. Upregulation of microRNA-98 increases radiosensitivity in esophageal squamous cell carcinoma. J. Radiat. Res 57, 468-476 (2016).

39. Guan, $H$. et al. Characterization and functional analysis of the human microRNA let-7a2 promoter in lung cancer A549 cell lines. Mol. Biol. Rep. 38 5327-5334 (2011)

40. Wagner, S., Ngezahayo, A., Murua Escobar, H. \& Nolte, I. Role of miRNA let-7 and its major targets in prostate cancer. Biomed. Res Int 2014, 376326 (2014).

41. Xue, F. et al. Let-7a enhances the sensitivity of hepatocellular carcinoma cells to cetuximab by regulating STAT3 expression. Onco Targets Ther. 9, 7253-7261 (2016). 